\title{
Does the Addition of Non-Approved Inclusion and Exclusion Criteria for rtPA Impact Treatment Rates? Findings in Australia, the UK, and the USA
}

\author{
Louise E. Craig a, b Sandy Middleton ${ }^{a}$ Helen Hamilton ${ }^{a}$ Fern Cudlip ${ }^{c}$ \\ Victoria Swatzell $^{d}$ Andrei V. Alexandrov ${ }^{e}$ Elizabeth Lightbody ${ }^{f}$ \\ Dame Caroline Watkins ${ }^{9}$ Sheeba Philiph ${ }^{h}$ Dominique A. Cadilhac ${ }^{i, j}$ \\ Elizabeth Mclnnes ${ }^{a}$ Simeon Dale ${ }^{a}$ Anne W. Alexandrov d, k

\begin{abstract}
aNursing Research Institute, St Vincent's Health AUS (Sydney) and Australian Catholic University, Sydney, NSW, Australia; ${ }^{b}$ Centre for Research in Evidence-Based Practice (CREBP), Bond University, Robina, QLD, Australia; 'Stroke Team, Good Samaritan Comprehensive Stroke Center, San Jose, CA, USA; d Mobile Stroke Unit, University of Tennessee Health

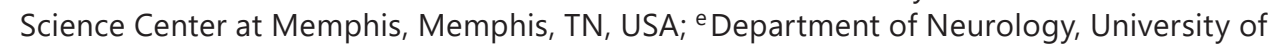
Tennessee Health Science Center at Memphis, Memphis, TN, USA; ${ }^{f}$ College of Health and Wellbeing, University of Central Lancashire, Preston, UK; ${ }^{9}$ Faculty of Health and Wellbeing, University of Central Lancashire, Preston, UK; ${ }^{\text {h}}$ East Lancashire Hospitals NHS Trust, Blackburn, UK; i Stroke and Ageing Research, School of Clinical Sciences at Monash Health, Monash University, Clayton, VIC, Australia; ${ }^{j}$ Florey Institute of Neuroscience and Mental Health, University of Melbourne, Parkville, VIC, Australia; ${ }^{k}$ College of Medicine, Department of Neurology \& College of Nursing, University of Tennessee Health Science Center at Memphis, Memphis, TN, USA
\end{abstract}

\section{Keywords}

Recombinant tissue plasminogen activator · Thrombolysis · Eligibility criteria · Survey

\begin{abstract}
Background: Strict criteria for recombinant tissue plasminogen activator (rtPA) eligibility are stipulated on licences for use in ischaemic stroke; however, practitioners may also add nonstandard rtPA criteria. We examined eligibility criteria variation in 3 English-speaking countries including use of non-standard criteria, in relation to rtPA treatment rates. Methods: Surveys were mailed to 566 eligible hospitals in Australia (AUS), the UK, and the USA. Criteria were pre-classified as standard (approved indication and contraindications) or non-standard (approved warning or researcher "decoy"). Percentage for criterion selection was calculated/ compared; linear regression was used to assess the association between use of non-standard criteria and rtPA treatment rates, and to identify factors associated with addition of non-
\end{abstract}


standard criteria. Results: Response rates were 74\% AUS, 65\% UK, and 68\% USA; mean rtPA treatment rates were $8.7 \%$ AUS, $12.7 \%$ UK, and $8.7 \%$ USA. Median percentage of non-standard inclusions was 33\% (all 3 countries) and included National Institutes of Health Stroke Scale (NIHSS) scores $>4$, computed tomography (CT) angiography documented occlusion, and favourable CT perfusion. Median percentage of non-standard exclusions was $25 \%$ AUS, $28 \%$ UK, and $60 \%$ USA, and included depressed consciousness, NIHSS $>25$, and use of antihypertensive infusions. No AUS or UK sites selected $100 \%$ of standard exclusions. Conclusions: Non-standard criteria for rtPA eligibility were evident in all three countries and could, in part, explain comparably low use of rtPA. Differences in the use of standard criteria may signify practitioner intolerance for those derived from original efficacy studies that are no longer relevant.

(c) 2018 S. Karger AG, Basel

\section{Introduction}

Intravenous thrombolysis with recombinant tissue plasminogen activator (rtPA) has been shown to be safe and effective and is one of the few evidence-based treatments for acute ischaemic stroke [1-5]. Currently, the percentage of patients with ischaemic stroke receiving rtPA varies globally, with 7\% treated in the stroke centre certified USA hospitals [6], 7\% in Australia (AUS) [7], and 12\% treated in the UK [8]. The narrow time frame for therapeutic administration, which in the UK and AUS is within $4.5 \mathrm{~h}$ of symptom onset and in the USA is within 3 (approved indication) or 4.5 (guidelines) h, is one main factor for low treatment rates. However, improved rtPA treatment rates are possible when internal hospital organisational factors are addressed [9-12], and when regional stroke systems are operationalised to support patients with acute stroke [13-16].

Eligibility criteria for rtPA are largely derived from clinical trials with the aim of producing similar beneficial outcomes in routine practice. However, the addition of local or "site-specific" (non-standard) eligibility criteria may result in otherwise eligible patients not receiving rtPA. There is a growing evidence base on the additional reasons for low rtPA treatment rates, including the fit between eligibility criteria and actual patient selection practices [17-19]. In particular, many of the criteria used in clinical trials may no longer be relevant given that the drug was first approved over 20 years ago [20-22]. Mounting evidence from pooled analyses, observational studies and clinical trials, some studying an extended time window of $4.5 \mathrm{~h}$ and practices less adherent with standard criteria, suggests that rtPA can be delivered safely to patients previously deemed ineligible [22-31].

The eligibility criteria for rtPA administration varies between countries [32-35]. The European and Australian guidelines share many similarities, but these differ substantially from the USA guidelines, and the USA guidelines vary significantly from the drug's approved indications and contraindications. Varying criteria between national drug regulatory bodies, professional organisations, and individual hospital protocols challenge international consensus on what constitutes patient eligibility for treatment. There is an urgent need to understand these issues, including the addition of non-standard criteria for selecting patients eligible for rtPA treatment. The aims of this study were to: (1) describe the criteria for patient selection for rtPA treatment by country; (2) to determine the association between the use of non-standard criteria and rtPA treatment rates in three different countries; and (3) to identify the organisational factors associated with the addition of non-standard criteria. 
Craig et al.: Does the Addition of Non-Approved Inclusion and Exclusion Criteria for rtPA Impact Treatment Rates? Findings in Australia, the UK, and the USA

\section{Methods}

We undertook a cross-sectional survey of rtPA eligibility and treatment practices within hospitals in Australia, the UK, and the USA that routinely used rtPA for management of acute stroke patients. The survey was conducted between 2013 and 2016 and analysed in 2017.

\section{Hospital Selection}

All hospitals in AUS and in the UK known to provide rtPA for acute ischaemic stroke were eligible for the study and were identified via the Stroke Foundation Organisational Survey [36] and The Sentinel Stroke National Audit Programme (SSNAP), respectively. In the USA, stroke centre hospitals were included based on the following inclusion criteria: (1) nationally certified by The Joint Commission for a minimum of 12 months at the time of survey mailing; (2) use of an organised acute stroke team in the approach to emergency diagnosis and treatment; and (3) formal identification by policy and procedure of eligibility criteria for rtPA treatment.

\section{Survey Distribution}

Within each hospital, one eligible staff member was identified to complete the survey: the Stroke Unit Co-ordinator in AUS and the USA and the SSNAP lead contact for the Trust in the UK identified staff who were approached by mail (AUS and USA) or email (UK) with a letter inviting them to participate in the survey along with a copy of the questionnaire. Prior to this invitation, an advanced letter was sent to notify potential participants of the pending survey as a response-aiding strategy [37]. Participation was voluntary, and consent was implied by completion and return of the questionnaire. Completed questionnaires were returned via post or fax, or completed and returned electronically. Non-respondents were followed-up by email or phone at 6 weeks and 8 weeks in AUS and the UK. In the USA, follow-up consisted of a second and third mail out at 8 and 16 weeks from the initial mail out date.

\section{Survey Content and Development}

The survey was originally designed for study in the USA and included both standard criteria for rtPA use in stroke patients (criteria stipulated by the USA rtPA approved indications and contraindications and/ or guidelines) and non-standard criteria (i.e., decoys derived from interviews with both expert users and community neurologists in the USA). This survey was then tailored for use in AUS and UK by adding criteria specified by the relevant country: (i) manufacturer, (ii) drug regulatory body, and (iii) stroke clinical guidelines (referred collectively as "practice recommendations" hereafter). The Australian and UK version of the survey was pre-tested with a panel of experts (Neurologists, Stroke Clinicians, and Stroke Nurses) to identify any ambiguous questions and to recommend further decoy criteria. All three versions of the surveys consisted of two main sections; one section listed all the inclusion criteria, and one section listed all the exclusion criteria. Participants were instructed to select all of the criteria that were used at their hospital to assess if patients are eligible for rtPA. Additional space was provided for participants to write in criteria that were not included on the questionnaire. Information was also collected on organisational factors which included type of stroke service (tertiary/non-tertiary referral centre), number of beds, number of ischaemic stroke admissions in the last 12 months, rtPA treatments in the last 12 months, door-to-needle time, and who was involved in the selection and decision-making process for rtPA.

\section{Data Analysis}

Descriptive analyses were used to summarise the self-reported characteristics of the stroke services by country. Criteria for patient selection for rtPA were pre-classified as either "standard" (an inclusion or exclusion specified by country practice recommendations) or "non-standard" (warnings specified by country practice recommendations or decoy criteria developed by the researchers). To determine criteria being used, the percentage of respondents that selected each criterion was calculated. For each hospital, the proportion of standard and non-standard criteria of the total criteria was calculated. The proportion calculated for each hospital was summarised for each country and reported as a median percentage. Criteria added by respondents were independently reviewed by study investigators (L.E.C., H.H., A.W.A.), and classified to existing groups if meanings were similar or classified as non-standard criteria if meanings were unique. Treatment rates were calculated for each hospital using the number of annual rtPA treatments reported, divided by the number of annual ischemic stroke admissions, multiplied by 100. Independent Student $t$ tests and one-way analysis of variance (ANOVA) were undertaken to examine the associations between pre-specified stroke 
service variables (hospital setting [tertiary/non-tertiary] and door to needle times) and rtPA treatment rates in each country. Linear regression analyses were conducted for each of the countries to assess associations between non-standard criteria and rtPA treatment rates. Linear regression models were developed using preselected variables to identify organisational factors associated with the addition of non-standard criteria in each country. Analyses were conducted with Stata version 14.

\section{Results}

The response rates per country were 68\% (AUS 74\% [63/85], UK 65\% [93/144], and USA $68 \%$ [229/337]). Tertiary hospital staff made up 39\% of respondents overall (AUS 46\%; UK $53 \%$; USA $29 \%$ ), with $38 \%$ of AUS respondents and $69 \%$ of USA respondents reporting comprehensive stroke centre (CSC) capabilities (CSC status was not reported on the UK survey) (see online suppl. Table A; see www.karger.com/doi/10.1159/000493020 for all online suppl. material). Decision makers for treatment with rtPA in AUS and the USA were most commonly neurologists (84 and 87\%, respectively), whilst the majority of UK respondents selected stroke (usually geriatrician) physicians (99\%). Interestingly, 31\% of USA centres would only accept an rtPA order from a neurologist. Telemedicine was not used in $68 \%$ and $39 \%$ of AUS and UK respondents, respectively (not collected on USA survey) (online suppl. Table A).

\section{Differences in rtPA Treatment Rates}

Of responding stroke centres, 60 (95\%) AUS, 77 (83\%) UK, and 184 (80\%) USA centres included both their annual ischaemic stroke patient volumes and their annual rtPA treatment volumes enabling calculation of rtPA treatment rates. Mean rtPA treatment rate for Australia, UK, and USA were 8.7\% (SD = 5.8), 12.7\% (SD = 4.7), and 8.7\% (SD = 6.4), respectively. Online supplementary Table B shows differences in rtPA treatment rates by tertiary care designation and door-to-needle times. Rates for rtPA treatments were consistently higher for tertiary than non-tertiary hospitals and increased with shorter door-to-needle time for all three countries, although differences in mean rates were only significantly different for USA $(F 7.64 ; p<0.001)$.

\section{Selection of Inclusion Criteria for rtPA Treatment}

The median percentage of standard criteria selected by USA (50\%; IQR 25) respondents was less than that selected by AUS (100\%; IQR 33) and UK (100\%; IQR 0) respondents. The median percentage of non-standard criteria selected by respondents from all three countries was $33 \%$.

Table 1 lists standard and non-standard inclusion and exclusion criteria and their rates of selection by country. The standard USA-approved inclusion criterion, "Ability to start rtPA within $3 \mathrm{~h}$ from symptom onset," was selected by almost a quarter of USA respondents. The non-standard criterion for limiting inclusion to patients with National Institutes of Health Stroke Scale scores greater than 4 points was selected by about half of respondents from AUS (49\%) and the UK (51\%), and 35\% of USA respondents. The non-standard criterion for a favourable computed tomographic (CT) perfusion scan in patients inside the window for rtPA treatment was selected by $22 \%$ of AUS and $19 \%$ of USA respondents, whereas only $11 \%$ of UK respondents selected this criterion. Additionally, 21 and 26\% of AUS and USA respondents, respectively, required evidence of occlusion on CT angiography as an rtPA non-standard inclusion criterion, compared to $16 \%$ of UK respondents.

\section{Selection of Exclusion Criteria for rtPA Treatment}

The median percentage of standard exclusion criteria selected by USA (82\%; IQR 18) respondents was higher than that selected by AUS (66\%; IQR 24) and UK (64\%; IQR 25) 


\section{Interventional Neurology}

\begin{tabular}{l|l}
\hline Intervent Neurol 2019;8:1-12 \\
\hline DOI: 10.1159/000493020 & $\begin{array}{l}\text { (c) 2018 S. Karger AG, Basel } \\
\text { www.karger.com/ine }\end{array}$ \\
\hline
\end{tabular}

Craig et al.: Does the Addition of Non-Approved Inclusion and Exclusion Criteria for rtPA Impact Treatment Rates? Findings in Australia, the UK, and the USA

Table 1. Reported rt-PA eligibility criteria by country

\begin{tabular}{|c|c|c|c|}
\hline & $\begin{array}{l}\text { AUS } \\
(n=63) \\
n(\%)\end{array}$ & $\begin{array}{l}\text { UK } \\
(n=93) \\
n(\%)\end{array}$ & $\begin{array}{l}\text { USA } \\
(n=229) \\
n(\%)\end{array}$ \\
\hline \multicolumn{4}{|l|}{ Inclusion criteria } \\
\hline \multicolumn{4}{|l|}{ Standard all $(n=2)$} \\
\hline Clinical diagnosis of acute ischaemic stroke causing measurable neurological deficit & $58(92)$ & $89(96)$ & $180(79)$ \\
\hline Exclusion of intracranial haemorrhage by appropriate imaging techniques ${ }^{\mathrm{a}}$ & $59(94)$ & $90(97)$ & NA \\
\hline \multicolumn{4}{|l|}{ Standard USA only $(n=2)$} \\
\hline Age $>18$ years & $57(91)$ & $81(87)$ & $179(78)$ \\
\hline Ability to start $<3 \mathrm{~h}$ from symptom onset & $1(1.6)$ & $1(1.1)$ & $54(24)$ \\
\hline \multicolumn{4}{|l|}{ Standard UK and AUS ( $n=1)$; standard by USA guidelines/non-standard by USA label } \\
\hline Ability to start $<4.5 \mathrm{~h}$ from symptom onset & $62(98)$ & $92(99)$ & $172(75)$ \\
\hline \multicolumn{4}{|l|}{ Non-standard all $(n=4)$} \\
\hline NIHSS $>4$ & 31 (49) & $47(51)$ & $80(35)$ \\
\hline Favourable CTP penumbra. & $14(22)$ & $10(11)$ & $43(19)$ \\
\hline Occlusion on CTA & $13(21)$ & $15(16)$ & $60(26)$ \\
\hline Age $<80$ years, for $3-4.5 \mathrm{~h}$ since onset & $11(18)$ & $33(36)$ & $111(63)^{\mathrm{b}}$ \\
\hline \multicolumn{4}{|l|}{ Non-standard USA $(n=1)$} \\
\hline Order for IV rtPA given only by a neurologist & NA & NA & $71(31)$ \\
\hline
\end{tabular}

\section{Standard exclusion criteria}

Bleeding risk

Standard all $(n=12)$

Active internal bleeding

Clinical presentation suggestive of SAH, even if CT is normal

Known bleeding diathesis

INR $>1.7$

APTT greater than upper limit of normal on lab report

Prothrombin time $>15 \mathrm{~s}$

Platelet count of below $100,000 / \mathrm{mm}^{3}$

History of serious head trauma or ischaemic stroke within 3 months of this event

History of structural lesions including arteriovenous malformation, aneurysms, or tumours

History of intracranial haemorrhage at any point in the past

Past major surgery or serious trauma in past 3 months

Evidence of intracranial haemorrhage on CT scan

Standard USA only $(n=1)$

Systolic BP >185 mm Hg and/or diastolic BP >110 mm Hg at the time of rtPA treatment

Standard AUS and UK only $(n=10)$

Significant bleeding disorder at present or within last 6 months

Recent arterial puncture at a non-compressible site

Neoplasm with increased risk of bleeding

Manifest or recent severe or dangerous bleeding

Severe uncontrolled arterial hypertension

Systolic BP $>185$ or diastolic BP >110 mm Hg, or aggressive (IV) management

History of gastrointestinal or urinary tract haemorrhage within 21 days

Recent (less than 10 days) traumatic CPR or obstetrical delivery

Patients receiving other intravenous thrombolytic agents

Any current use of anticoagulation regardless of coagulation study findings

$\begin{array}{lll}59(94) & 85(91) & 181(79) \\ 54(86) & 78(83) & 150(66) \\ 51(81) & 75(81) & 160(70) \\ 59(94) & 86(93) & 179(78) \\ 37(59) & 47(51) & 163(71) \\ 19(30) & 24(26) & 113(49) \\ 47(75) & 53(57) & 170(74) \\ 52(83) & 78(84) & 180(79) \\ & & \\ 49(78) & 71(76) & 161(70) \\ 45(71) & 72(77) & 194(85) \\ 43(68) & 64(69) & 174(76) \\ 50(79) & 83(89) & \mathrm{NA}^{\mathrm{c}}\end{array}$

Stroke severity and/or disability

Standard AUS and UK $(n=4)$

Symptoms beginning more than $4.5 \mathrm{~h} /$ unknown onset time

Severe neurological disability, e.g. NIHSS $>25$

Prior stroke within the last 3 months

Rapidly improving stroke symptoms, even if measurable disability remains

$\begin{array}{lll}\text { NA } & \text { NA } & 181(79) \\ 40(64) & 69(74) & \text { NA } \\ 47(75) & 73(79) & 153(67) \\ 35(56) & 60(65) & \text { NA } \\ 40(64) & 73(79) & \text { NA } \\ 40(64) & 60(65) & \text { NA } \\ 49(78) & 54(58) & \text { NA } \\ 45(71) & 73(79) & 163(71) \\ 39(62) & 64(69) & \text { NA } \\ 31(49) & 58(62) & \text { NA } \\ 14(22) & 15(16) & 51(22)\end{array}$

$\begin{array}{lll}48(76) & 72(77) & \text { NA } \\ 39(62) & 39(42) & 70(31) \\ 37(59) & 58(62) & \text { NA } \\ 22(35) & 40(43) & 100(44)\end{array}$




\section{Interventional Neurology}

\begin{tabular}{l|l}
\hline Intervent Neurol 2019;8:1-12 \\
\hline DOI: 10.1159/000493020 & $\begin{array}{l}\text { (c) 2018 S. Karger AG, Basel } \\
\text { www.karger.com/ine }\end{array}$ \\
\hline
\end{tabular}

Craig et al.: Does the Addition of Non-Approved Inclusion and Exclusion Criteria for rtPA Impact Treatment Rates? Findings in Australia, the UK, and the USA

Table 1 (continued)

\begin{tabular}{|c|c|c|c|}
\hline & $\begin{array}{l}\text { AUS } \\
(n=63) \\
n(\%)\end{array}$ & $\begin{array}{l}\text { UK } \\
(n=93) \\
n(\%)\end{array}$ & $\begin{array}{l}\text { USA } \\
(n=229) \\
n(\%)\end{array}$ \\
\hline \multicolumn{4}{|l|}{ Comorbidity } \\
\hline \multicolumn{4}{|l|}{ Standard all $(n=1)$} \\
\hline Observed seizure at stroke onset & $45(71)$ & $53(57)$ & $122(53)$ \\
\hline \multicolumn{4}{|l|}{ Standard UK and AUS only $(n=7)$} \\
\hline Suspected post-myocardial infarction pericarditis & $21(33)$ & $36(39)$ & $77(34)$ \\
\hline Acute pancreatitis & $20(32)$ & $55(59)$ & NA \\
\hline Suspicion of endocarditis & $32(51)$ & $47(51)$ & $58(25)$ \\
\hline $\begin{array}{l}\text { Severe liver disease, including hepatic failure, cirrhosis, portal hypertension, and } \\
\text { active hepatitis }\end{array}$ & $35(56)$ & $58(62)$ & NA \\
\hline Abnormal blood glucose; $<50 \mathrm{mg} / \mathrm{dL}(<2.8 \mathrm{mmol} / \mathrm{L})$ or $>400 \mathrm{mg} / \mathrm{dL}(22.2 \mathrm{mmol} / \mathrm{L})$ & $53(84)$ & $53(57)$ & $133(58)$ \\
\hline $\begin{array}{l}\text { Documented ulcerative gastrointestinal disease (last } 3 \text { months), oesophageal } \\
\text { varices, arterial aneurysm, arterial/venous malformation }\end{array}$ & $40(64)$ & $73(79)$ & NA \\
\hline Patients with any history of prior stroke and concomitant diabetes & $9(14)$ & $19(20.4)$ & NA \\
\hline \multicolumn{4}{|l|}{ Demographics } \\
\hline \multicolumn{4}{|l|}{ Standard UK and AUS only $(n=1)$} \\
\hline Age $<18$ years & $38(60)$ & $59(63)$ & NA \\
\hline \multicolumn{4}{|l|}{ Non-standard exclusion criteria } \\
\hline \multicolumn{4}{|l|}{ Bleeding risk $(n=5)$} \\
\hline Current use of novel anticoagulants (NOACS) & $36(57)$ & $67(72)$ & $132(58)$ \\
\hline Use of continuous intravenous infusion to control blood pressure & $18(29)$ & $22(24)$ & $17(7.0)$ \\
\hline Patients pre-treated with acetyl salicylic acid & $1(1.6)$ & $7(7.5)$ & NA \\
\hline On other antiplatelet medication ${ }^{\mathrm{d}}$ & NA & NA & $12(5.2)$ \\
\hline Other conditions deemed high risk for haemorrhage ${ }^{d}$ & $3(4.8)$ & $2(2.2)$ & NA \\
\hline \multicolumn{4}{|l|}{ Stroke severity and/or disability $(n=4)$} \\
\hline Level of consciousness severely depressed (obtunded, stuporous or comatose) & $39(62)$ & $39(42)$ & $16(7.0)$ \\
\hline Minor neurological disability & $23(37)$ & $29(31)$ & $59(26)$ \\
\hline History of previous ischaemic stroke at any point in the past & $5(7.9)$ & $7(7.5)$ & NA \\
\hline Large artery occlusion warranting primary intra-arterial treatment & $1(1.6)$ & $8(8.6)$ & $31(14)$ \\
\hline \multicolumn{4}{|l|}{ Comorbidity $(n=11)$} \\
\hline Pregnancy & $47(75)$ & $38(41)$ & $112(49)$ \\
\hline Concurrent acute myocardial infarction & $30(48)$ & $15(16)$ & $60(26)$ \\
\hline Serious, advanced or terminal illness ${ }^{\mathrm{d}}$ & $8(13)$ & 0 & NA \\
\hline Suspected septic emboli $^{\mathrm{d}}$ & $8(13)$ & 0 & NA \\
\hline Elevated liver enzymes & $4(6.4)$ & $17(18)$ & NA \\
\hline Not observed, but suspected seizure at stroke onset & $18(29)$ & $21(23)$ & $45(20)$ \\
\hline Pre-existing moderate to severe disability $(\mathrm{mRS}>3 / 4)^{\mathrm{d}}$ & $7(11)$ & $9(9.7)$ & NA \\
\hline Known hypersensitivity to alteplase or gentamicin ${ }^{\mathrm{d}}$ & $5(7.9)$ & 0 & NA \\
\hline Recent lumbar puncture & $24(38)$ & $50(54)$ & $114(50)$ \\
\hline Myocardial infarction in last 3 months ${ }^{\mathrm{d}}$ & $1(1.6)$ & 0 & NA \\
\hline Lactation or parturition in last 30 days $^{\mathrm{d}}$ & $1(1.6)$ & 0 & NA \\
\hline \multicolumn{4}{|l|}{ Demographics $(n=4)$} \\
\hline Age $>75$ years & 0 & 0 & NA \\
\hline Age $>80$ years & $8(13)$ & $3(3.2)$ & $36(16)$ \\
\hline Only to be used by physicians trained and experienced in the use of thrombolytic & & & \\
\hline treatment & $11(18)$ & $40(43)$ & NA \\
\hline Inability to obtain written informed consent for on-label treatment & $5(7.9)$ & $3(3.2)$ & $21(9.2)$ \\
\hline
\end{tabular}

NA, not applicable, refers to a criterion that was not pre-specified in the country-specific survey; SAH, subarachnoid haemorrhage; CT, computed tomography; CTP, computed tomography perfusion; CTA, computed tomography angiography; INR, international normalised ratio; APTT, activated partial thromboplastin time; BP, blood pressure; CPR, cardiopulmonary resuscitation; NIHSS, National Institute of Health's Stroke Scale; mRS, Modified Rankin Scale; ROSIER, Recognition of Stroke in the Emergency Room Scale.

${ }^{\mathrm{a}}$ This was specified as an exclusion on the USA survey and therefore not specified on inclusions. ${ }^{\mathrm{b}}$ The 54 respondents that selected

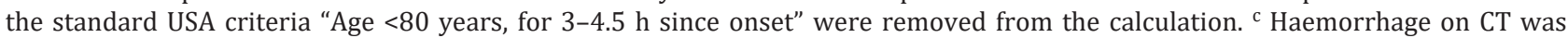
specified as an exclusion on the USA survey, so these data were not collected. ${ }^{\mathrm{d}}$ This was specified as an "other" by respondents. 
respondents. The median percentage of non-standard exclusions selected by USA respondents (60\%; IQR 60) was again higher than that selected by AUS (25\%; IQR 19) and UK (28\%; IQR 17) respondents.

There were no respondents within AUS or the UK that selected all their country's standard exclusion criteria, and all AUS and UK respondents added non-standard exclusion criteria. Both "NIHSS $>25$ " and "altered level of consciousness (obtunded, stuporous, or comatose)" were selected by 62 and $42 \%$ of AUS and UK respondents, respectively, whereas $31 \%$ of USA respondents reported that their hospital excluded patients with NIHSS $>25$, and $7 \%$ of USA respondents' hospitals excluded patients with altered level of consciousness. Additionally, 29,24 , and $7 \%$ of AUS, UK, and USA respondents indicated that their hospital excludes patients from rtPA treatment if they require a continuous IV infusion of an antihypertensive agent. Patients with large vessel occlusion (LVO) were considered an exclusion for rtPA treatment by $14 \%$ of USA respondents, in favour of endovascular management, whereas 1.6 and $8.6 \%$ of AUS and UK respondents, respectively, reported that their hospitals exclude LVO from rtPA treatment in favour of endovascular treatment. Age greater than 80 years was listed as an exclusion by 13 and $16 \%$ of AUS and USA respondents, respectively, compared to only $3 \%$ of UK respondents, regardless of whether treating within the 3- or 4.5-h treatment window.

\section{Relationship of Non-Standard Criteria to rtPA Treatment}

As the number of non-standard inclusions and exclusions increased, rtPA treatment rates slightly decreased in all three countries. As the number of non-standard criteria increased by one, the rtPA rate decreased by $0.48 \%(p=0.05), 0.31 \%(p=0.07)$, and $0.16 \%(p=0.13)$ for AUS, UK, and the USA, respectively.

\section{Association between Factors and the Addition of Non-Standard Criteria}

Factors significantly associated with the addition of non-standard criteria in the USA were as follows: non-tertiary hospital setting $(-1.72$ [95\% CI $-3.25,-0.20] ; p$ value $=0.03)$; average door-to-needle time greater than $60 \min (3.57$ [95\% CI $-0.38,6.75] ; p$ value $=0.023)$; and adherence to 3 -h treatment window $(-2.44$ [95\% CI $-4.30,-0.60] ; p$ value $=0.01)$. No factors were significantly associated with the addition of non-standard criteria in AUS or in the UK (online suppl. Table C).

\section{Discussion}

Our study found that clinicians commonly develop and use non-standard criteria for selection of rtPA-eligible patients. Importantly, both AUS and the UK have greater numbers of standard criteria compared to the USA, yet participants from these countries use more nonstandard criteria than participants in the USA. The use of non-standard exclusion criteria has been investigated in other studies; however, the aims of most of these studies were to identify the impact of non-standard eligibility criteria on early clinical outcomes such as rates of symptomatic intracerebral haemorrhage (sICH) [20-23, 38]. To the best of our knowledge, our study appears to be the only one examining clinicians' formal protocol additions of nonstandard criteria in relation to rtPA treatment rates.

There were a number of differences in the criteria between countries relating to the use of both standard and non-standard exclusion criteria. Differences in use of standard criteria between countries could signify clinical uncertainty, conflicting research evidence, or perhaps an intolerance for continued use of criteria that supported efficacy studies of rtPA in acute ischemic stroke but may not be relevant outside a phase III clinical trial. For example, both severe neurologic disability and blood glucose limits were considered warnings but not 
contraindications on the former (prior to February 2015) [39] USA label for rtPA, whereas the Australian and UK labels continue to stipulate specific limits from which to exclude rtPA treatment. Interestingly, the February 2015 USA Food and Drug Administration (FDA) rtPAapproved label [39] removed severe neurologic disability as a precaution, based on findings from the original National Institute of Neurological Disorders and Stroke rtPA Stroke Study that showed significant improvement in severe disability patients treated with rtPA compared to placebo [40]. Similarly, the 2015 USA FDA-approved label [39] no longer cites blood glucose values as warnings, as these are easily monitored and managed in both the pre-hospital and emergency department settings.

The use of some standard exclusions was fewer than expected in both AUS and the UK. For example, less than $25 \%$ of participants in these countries selected the standard exclusion, patients with any history of prior stroke and concomitant diabetes. Although the use of rtPA has not been approved in Europe for these patients, registry studies have shown that while this criterion may have been important in the ECASS-3 efficacy study [2], it may not be relevant to real-world practice and does not jeopardise the safe treatment of patients with rtPA [41, 42]. While trial methods do provide a degree of certainty about what results to expect in a similar population, use of approved therapies in the real world often calls for less exclusivity [43].

It has been recognised internationally that selection criteria may be too restrictive, and some have expressed concerns that the evidence underpinning the need to include certain criteria is not robust [20-28, 43-45]. The 2015 USA FDA labelling requirements for prescription drugs, commonly referred to as the "Physician Labelling Rule" (PLR), state "No implied claims or suggestions of drug use may be made if there is inadequate evidence of safety or a lack of substantial evidence of effectiveness [46]," meaning that unless there is high-level evidence to support a safety concern, it should not be considered a contraindication. The USA FDA's PLR requirements significantly reduced the number of USA exclusion criteria to seven in 2015, with previous stroke, seizure at onset, and history of intracranial

haemorrhage removed; additionally, blood pressure cut-off levels, as well as lab values for bleeding diathesis were also removed in favour of relying on evidence-based guidelines to set these values [39]. The 2015 USA FDA label also removed precautions for severe neurologic deficit, major early infarct signs, minor neurologic deficit, and rapidly improving symptoms [39]. Interestingly, the majority of the USA criteria that were removed, currently remain on the European and Australian labels, and we believe that this calls for a more thorough evaluation of whether these criteria are truly valid perhaps using the processes established by The Re-examining Acute Eligibility for Thrombolysis (TREAT) Task Force, which is composed of members of the original NINDS rtPA Stroke Trial Steering Committee [44], especially with sICH rates from more recent studies and registries commonly at less than $3 \%[2,47-51]$. The investigators of a recent study which aimed to assess whether adherence to drug labels is associated with efficacious patient outcomes concluded that product labels need to be revised, finding that adherence with product labels is highest with less efficacious interventions [52].

\section{Limitations}

This study carries the limitations of survey research such as the risk of response and recall bias. First, we assume that findings submitted are truthful and accurately reflect the practice at the participating stroke centres, although this may not be the case. We also acknowledge that some items such as aortic arch dissection were not listed as criteria in the questionnaire for participants to select. Additionally, surveys do not provide the meaning or context behind a response. Therefore, we are limited in our ability to provide an understanding of why and how clinicians make certain decisions including their areas of clinical or research uncertainty [53]. Lastly, although this questionnaire was personally addressed to 
Stroke Unit Coordinators, a variety of professional groups responded; while this was anticipated and encouraged by our instructions to "collaborate with colleagues, who are involved in the decision-making and administration of rtPA for stroke patients," it does potentially introduce a source of differential error and measurement error. Furthermore, this is a highly dynamic field, with new imagining criteria re-defining reperfusion strategies at different time points $[54,55]$. Therefore, it would be worthwhile to repeat this study as the reperfusion paradigm shifts.

\section{Strengths}

This research provides novel data about rtPA international administration practices and the differences in the use of selection criteria in three different countries, two with similar healthcare systems (AUS/UK), and the USA with a largely private health system. The survey had a reasonable response rate for all three countries, which adds external validity to the findings, and our survey tools were extensively pre-tested with experts contributing face validity to our methods.

\section{Conclusion}

This study provides novel, and somewhat provocative data about the criteria used to select patients for rtPA across three English-speaking countries, in particular the relatively common use of non-standard criteria for rtPA eligibility which may contribute in part, to low rtPA treatment rates.

\section{Statement of Ethics}

Ethics approval was obtained from the following institutions for the conduct of this study: Eden Hospital, Castro Valley California (USA coordinating centre), the University of Central Lancashire (UK coordinating centre), and the Australian Catholic University (Australian, and overall international coordinating centre).

\section{Disclosure Statement}

Anne W. Alexandrov and Andrei V. Alexandrov are members of the Genentech Speakers Bureau. All other authors declare that there are no competing interests.

\section{Funding Sources}

This project was supported by an infrastructure grant provided by the Australian Catholic University to support the International Stroke Research Collaboration. D.A.C. was supported by a fellowship from the National Health and Medical Research Council (NHMRC; 1063761 co-funded by National Heart Foundation).

\section{Author Contributions}

A.W.A., F.C., and V.S. conceived the study. A.W.A., A.V.A., L.E.C., S.M., D.A.C., and C.W. designed the study. L.E.C., H.H. and E.L. conducted all analyses. The paper was jointly written and reviewed by all authors. 
Craig et al.: Does the Addition of Non-Approved Inclusion and Exclusion Criteria for rtPA Impact Treatment Rates? Findings in Australia, the UK, and the USA

\section{References}

1 The National Institute of Neurological Disorders and Stroke rtPA Stroke Study Group. Tissue plasminogen activator for acute ischemic stroke. N Engl J Med. 1995;333(24):1581-7.

2 Hacke W, Kaste M, Bluhmki E, Brozman M, Dávalos A, Guidetti D, et al.; ECASS Investigators. Thrombolysis with alteplase 3 to 4.5 hours after acute ischemic stroke. N Engl J Med. 2008 Sep;359(13):1317-29.

3 Emberson J, Lees KR, Lyden P, Blackwell L, Albers G, Bluhmki E, et al.; Stroke Thrombolysis Trialists' Collaborative Group. Effect of treatment delay, age, and stroke severity on the effects of intravenous thrombolysis with alteplase for acute ischaemic stroke: a meta-analysis of individual patient data from randomised trials. Lancet. 2014 Nov;384(9958):1929-35.

4 Wardlaw J, Murray V, Berge E, del Zoppo G. Thrombolysis for acute ischaemic stroke. Cochrane Database Syst Rev. 2014 Jul 29;(7):CD000213.

5 Tsivgoulis G, Katsanos AH, Mavridis D, Alexandrov AW, Magoufis G, Arthur A, et al. Endovascular thrombectomy with or without systemic thrombolysis? Ther Adv Neurol Disorder. 2017 Mar;10(3):151-60.

6 Schwamm LH, Ali SF, Reeves MJ, Smith EE, Saver JL, Messe S, et al. Temporal trends in patient characteristics and treatment with intravenous thrombolysis among acute ischemic stroke patients at Get With The Guidelines-Stroke hospitals. Circ Cardiovasc Qual Outcomes. 2013 Sep;6(5):543-9.

7 National Stroke Foundation National Stroke Audit - Acute Services Report 2017. Melbourne, National Stroke Foundation; 2017.

8 Royal College of Physicians, Clinical Effectiveness and Evaluation Unit on behalf of the Intercollegiate Stroke Working Party. Sentinel Stroke National Audit Programme (SSNAP). Changes over Time: 4 years of data. April 2013-March 2017.

9 Meretoja A, Strbian D, Mustanoja S, Tatlisumak T, Lindsberg PJ, Kaste M. Reducing in-hospital delay to 20 minutes in stroke thrombolysis. Neurology. 2012 Jul;79(4):306-13.

10 Meretoja A, Weir L, Ugalde M, Yassi N, Yan B, Hand P, et al. Helsinki model cut stroke thrombolysis delays to 25 minutes in Melbourne in only 4 months. Neurology. 2013 Sep;81(12):1071-6.

11 Paul CL, Ryan A, Rose S, Attia JR, Kerr E, Koller C, et al. How can we improve stroke thrombolysis rates? A review of health system factors and approaches associated with thrombolysis administration rates in acute stroke care. Implement Sci. 2016 Apr;11(1):51.

12 Middleton S, Grimley R, Alexandrov AW. Triage, treatment, and transfer: evidence-based clinical practice recommendations and models of nursing care for the first 72 hours of admission to hospital for acute stroke. Stroke. 2015 Feb;46(2):e18-25.

13 Skolarus LE, Meurer WJ, Shanmugasundaram K, Adelman EE, Scott PA, Burke JF. Marked regional variation in acute stroke treatment among Medicare beneficiaries. Stroke. 2015 Jul;46(7):1890-6.

14 Eng MS, Patel AV, Libman RB, Wright P, Katz JM. Improving regional stroke systems of care. Curr Atheroscler Rep. 2017 Oct;19(12):52.

15 Bagot KL, Cadilhac DA, Hand PJ, Vu M, Bladin CF. Telemedicine expedites access to optimal acute stroke care. Lancet. 2016 Aug;388(10046):757-8.

16 Rhudy JP Jr, Bakitas MA, Hyrkäs K, Jablonski-Jaudon RA, Pryor ER, Wang HE, et al. Effectiveness of regionalized systems for stroke and myocardial infarction. Brain Behav. 2015 Sep;5(10):e00398.

17 Hills NK, Johnston SC. Why are eligible thrombolysis candidates left untreated? Am J Prev Med. 2006 Dec;31(6 Suppl 2):S210-6.

18 Keyhani S, Arling G, Williams LS, Ross JS, Ordin DL, Myers J, et al. The use and misuse of thrombolytic therapy within the Veterans Health Administration. Med Care. 2012 Jan;50(1):66-73.

19 Messé SR, Khatri P, Reeves MJ, Smith EE, Saver JL, Bhatt DL, et al. Why are acute ischemic stroke patients not receiving IV tPA? Results from a national registry. Neurology. 2016 Oct;87(15):1565-74.

20 Breuer L, Blinzler C, Huttner HB, Kiphuth IC, Schwab S, Köhrmann M. Off-label thrombolysis for acute ischemic stroke: rate, clinical outcome and safety are influenced by the definition of 'minor stroke'. Cerebrovasc Dis. 2011;32(2):177-85.

21 Guillan M, Alonso-Canovas A, Garcia-Caldentey J, Sanchez-Gonzalez V, Hernandez-Medrano I, DefelipeMimbrera A, et al. Off-label intravenous thrombolysis in acute stroke. Eur J Neurol. 2012 Mar; 19(3): 390-4.

22 Frank B, Grotta JC, Alexandrov AV, Bluhmki E, Lyden P, Meretoja A, et al.; VISTA Collaborators. Thrombolysis in stroke despite contraindications or warnings? Stroke. 2013 Mar;44(3):727-33.

23 Lyerly MJ, Albright KC, Boehme AK, Bavarsad Shahripour R, Houston JT, Rawal PV, et al. Safety of protocol violations in acute stroke tPA administration. J Stroke Cerebrovasc Dis. 2014 May-Jun;23(5):855-60.

24 Tsivgoulis G, Zand R, Katsanos AH, Sharma VK, Goyal N, Krogias C, et al. Safety and outcomes of intravenous thrombolysis in dissection-related ischemic stroke: an international multicenter study and comprehensive meta-analysis of reported case series. J Neurol. 2015 Sep;262(9):2135-43.

25 Goyal N, Tsivgoulis G, Zand R, Sharma VK, Barlinn K, Male S, et al. Systemic thrombolysis in acute ischemic stroke patients with unruptured intracranial aneurysms. Neurology. 2015 Oct;85(17):1452-8.

26 Tsivgoulis G, Katsanos AH, Zand R, Sharma VK, Köhrmann M, Giannopoulos S, et al. Antiplatelet pretreatment and outcomes in intravenous thrombolysis for stroke: a systematic review and meta-analysis. J Neurol. 2017 Jun;264(6):1227-35. 
27 Hacke W, Kaste M, Bluhmki E, Brozman M, Dávalos A, Guidetti D, et al. Thrombolysis with alteplase 3 to 4.5 hours after acute ischemic stroke. N Engl J Med. 2008 Sep 25;359(13):1317-29.

28 Meretoja A, Putaala J, Tatlisumak T, Atula S, Artto V, Curtze S, et al. Off-label thrombolysis is not associated with poor outcome in patients with stroke. Stroke. 2010 Jul;41(7):1450-8.

29 Zand R, Tsivgoulis G, Sadighi A, Singh M, McCormack M, Shahjouei S, et al. Safety of Intravenous Thrombolysis in Chronic Intracranial Hemorrhage: A Five-Year Multicenter Study. J Stroke Cerebrovasc Dis. 2018 Mar; 27(3):620-4.

30 Tsivgoulis G, Katsanos AH, Kadlecová P, Czlonkowska A, Kobayashi A, Brozman M, et al. Intravenous thrombolysis for patients with in-hospital stroke onset: propensity-matched analysis from the Safe Implementation of Treatments in Stroke-East registry. Eur J Neurol. 2017 Dec;24(12):1493-8.

31 Tsivgoulis G, Safouris A, Alexandrov AV. Safety of intravenous thrombolysis for acute ischemic stroke in specific conditions. Expert Opin Drug Saf. 2015 Jun;14(6):845-64.

32 US Food and Drug Administration. Alteplase product approval information - licensing action 6/18/96. 04/02/2009. Food and Drug Administration, 1996.

33 Medicines and Healthcare Products Regulatory Authority. Summary of Product Charateristics - Actilyse. London, Medicines and Healthcare products Regulatory Authority, 2009.

34 Demaerschalk BM, Kleindorfer DO, Adeoye OM, Demchuk AM, Fugate JE, Grotta JC, et al.; American Heart Association Stroke Council and Council on Epidemiology and Prevention. Scientific Rationale for the Inclusion and Exclusion Criteria for Intravenous Alteplase in Acute Ischemic Stroke: A Statement for Healthcare Professionals From the American Heart Association/American Stroke Association. Stroke. 2016 Feb;47(2):581-641.

35 Campbell BC, Meretoja A, Donnan GA, Davis SM. Twenty-Year History of the Evolution of stroke thrombolysis with intravenous alteplase to reduce long-term disability. Stroke. 2015 Aug;46(8):2341-6.

36 National Stroke Foundation. National Stroke Audit Acute Services: Organisational Survey Report, 2013.

37 Edwards P, Roberts I, Clarke M, DiGuiseppi C, Pratap S, Wentz R, et al. Increasing response rates to postal questionnaires: systematic review. BMJ. 2002 May;324(7347):1183.

38 Aleu A, Mellado P, Lichy C, Köhrmann M, Schellinger PD. Hemorrhagic complications after off-label thrombolysis for ischemic stroke. Stroke. 2007 Feb;38(2):417-22.

39 Genetech Inc. ACTIVASE ${ }^{\circledR}$ (alteplase) for acute ischemic stroke indication. Updated Prescribing Information - summary of changes, 2015.

40 Group TN. Intracerebral hemorrhage after intravenous t-PA therapy for ischemic stroke. The NINDS t-PA Stroke Study Group. Stroke. 1997 Nov;28(11):2109-18.

41 Mishra NK, Ahmed N, Davalos A, Iversen HK, Melo T, Soinne L, et al.; SITS and VISTA collaborators. Thrombolysis outcomes in acute ischemic stroke patients with prior stroke and diabetes mellitus. Neurology. 2011 Nov; 77(21):1866-72.

42 Mishra NK, Davis SM, Kaste M, Lees KR; VISTA Collaboration. Comparison of outcomes following thrombolytic therapy among patients with prior stroke and diabetes in the Virtual International Stroke Trials Archive (VISTA). Diabetes Care. 2010 Dec;33(12):2531-7.

43 De Los Rios F, Kleindorfer DO, Guzik A, Ortega-Gutierrez S, Sangha N, Kumar G, et al.; SPOTRIAS Investigators. Intravenous fibrinolysis eligibility: a survey of stroke clinicians' practice patterns and review of the literature. J Stroke Cerebrovasc Dis. 2014 Sep;23(8):2130-8.

44 Re-examining Acute Eligibility for Thrombolysis (TREAT) Task Force: Levine SR, Khatri P, Broderick JP, Grotta JC, Kasner SE, et al. Review, historical context, and clarifications of the NINDS rtPA stroke trials exclusion criteria: Part 1: Rapidly improving stroke symptoms. Stroke. 2013 Sep;44(9):2500-5.

45 Cappellari M, Moretto G, Micheletti N, Donato F, Tomelleri G, Gulli G, et al. Off-label thrombolysis versus full adherence to the current European Alteplase license: impact on early clinical outcomes after acute ischemic stroke. J Thromb Thrombolysis. 2014 May;37(4):549-56.

46 Code of Federal Regulations. Requirements on content and format of labelling for human prescription drug and biological products. S201.56, S201.56. Sect. 21 CFR 201.56 (2016).

47 Ahmed N, Lees KR, Ringleb PA, Bladin C, Collas D, Toni D, et al.; The SITS Investigators. Outcome after stroke thrombolysis in patients $[\{G T\}] 80$ years treated within 3 hours vs $[\{G T\}] 3-4.5$ hours. Neurology. 2017 Oct; 89(15):1561-8.

48 Ahmed N, Kellert L, Lees KR, Mikulik R, Tatlisumak T, Toni D; SITS Investigators. Results of intravenous thrombolysis within 4.5 to 6 hours and updated results within 3 to 4.5 hours of onset of acute ischemic stroke recorded in the Safe Implementation of Treatment in Stroke International Stroke Thrombolysis Register (SITS-ISTR): an observational study. JAMA Neurol. 2013 Jul;70(7):837-44.

49 Mazya MV, Lees KR, Collas D, Rand VM, Mikulik R, Toni D, et al. IV thrombolysis in very severe and severe ischemic stroke: results from the SITS-ISTR Registry. Neurology. 2015 Dec;85(24):2098-106.

50 Lees KR, Ford GA, Muir KW, Ahmed N, Dyker AG, Atula S, et al.; SITS-UK Group. Thrombolytic therapy for acute stroke in the United Kingdom: experience from the safe implementation of thrombolysis in stroke (SITS) register. QJM. 2008 Nov;101(11):863-9.

51 Wahlgren N, Ahmed N, Dávalos A, Hacke W, Millán M, Muir K, et al.; SITS investigators. Thrombolysis with alteplase 3-4.5 hafter acute ischaemic stroke (SITS-ISTR): an observational study. Lancet. 20080ct;372(9646): 1303-9. 
52 Cameron AC, Bogie J, Abdul-Rahim AH, Ahmed N, Mazya M, Mikulik R, et al. Professional guideline versus product label selection for treatment with IV thrombolysis: an analysis from SITS registry. Eur Stroke J. 2017 Dec;3(1):39-46.

53 De Brún A, Flynn D, Ternent L, Price CI, Rodgers H, Ford GA, et al. Factors that influence clinicians' decisions to offer intravenous alteplase in acute ischemic stroke patients with uncertain treatment indication: results of a discrete choice experiment. Int J Stroke. 2018 Jan;13(1):74-82.

54 Nogueira RG, Jadhav AP, Haussen DC, Bonafe A, Budzik RF, Bhuva P, et al.; DAWN Trial Investigators. Thrombectomy 6 to 24 Hours after Stroke with a Mismatch between Deficit and Infarct. N Engl J Med. 2018 Jan; 378(1):11-21.

55 Albers GW, Marks MP, Kemp S, Christensen S, Tsai JP, Ortega-Gutierrez S, et al.; DEFUSE 3 Investigators. Thrombectomy for stroke at 6 to 16 hours with selection by perfusion imaging. N Engl J Med. 2018 Feb;378(8): 708-18. 